Table 1.

\begin{tabular}{|c|c|c|c|c|c|c|c|c|}
\hline$\#$ & Diagnosis & Indication & Previous biologics & $\begin{array}{c}\text { Current } \\
\text { treat-ment }\end{array}$ & $\begin{array}{l}\text { TOF, dose, } \\
\mathrm{mg} / \mathrm{kg}\end{array}$ & $\begin{array}{l}\text { Duration } \\
\text { of TOF treat- } \\
\text { ment, months }\end{array}$ & $\begin{array}{l}\text { Genetic } \\
\text { variants } \\
\text { detected }\end{array}$ & Efficacy \\
\hline 1 & AID & $\begin{array}{l}\text { Severe inflamma-tion, aortitis, } \\
\text { colitis }\end{array}$ & INX, TCZ, ADA & CS, TOF & 0.5 & 7 & $\begin{array}{c}\text { NOD2 c.2578G }>\text { A (p.A860T); NOD2 c.2722G }>C \\
\text { (p.G908R) } \\
\text { ADA2 c.927G }>\text { A (p.M309I) }\end{array}$ & PR \\
\hline 2 & JDM & recurrent skin rash & & CS, TOF, MTX & 0.5 & 5 & & PR \\
\hline 3 & JDM & skin involvement, ulceration & & CS, MTX, TOF & 0.7 & 7 & NLRP12c.154G>A (p.G52S) & $\mathrm{CR}$ \\
\hline 4 & $\begin{array}{l}\text { AID, } \\
\text { IFP }\end{array}$ & $\begin{array}{l}\text { skin rash, recurrent inflammation, } \\
\text { failure to thrive }\end{array}$ & CAN, TCZ & CS, TOF, CAN & 0.5 & 32 & $\begin{array}{c}\text { RNASEH2B } \\
\text { c.916dupA (p.1309Nfs*7) }\end{array}$ & CR \\
\hline 5 & $\begin{array}{l}\text { JIA, } \\
\text { poly }\end{array}$ & severe arthritis & $\begin{array}{c}\text { ETA,TCZ, } \\
\text { ADA }\end{array}$ & TOF,TCZ & 0.27 & 22 & & PR \\
\hline 6 & SOJIA & $\begin{array}{l}\text { resistant to CS and biologic } \\
\text { systemic inflammation, arthritis }\end{array}$ & $\begin{array}{l}\text { TCZ, ABC, } \\
\text { CAN }\end{array}$ & TOF, TCZ & 0.4 & 23 & & PR \\
\hline 7 & $\begin{array}{l}\text { JIA, } \\
\text { poly }(R F+) \\
\text { alopecia }\end{array}$ & $\begin{array}{c}\text { Severe arthritis, lung involvement, } \\
\text { alopecia }\end{array}$ & $\begin{array}{l}\text { ETA, ABC, } \\
\text { TCZ, ADA }\end{array}$ & TOF, MTX, CS & 0.3 & 37 & $\begin{array}{l}\text { IL1RN c.10G>C (p.A4P); NLRP3 c.2113C>A } \\
\text { (p.Q705L); MEFV c.1105C>T (p.P369S) }\end{array}$ & $\mathrm{CR}$ \\
\hline 8 & $\begin{array}{l}\text { IFP, CANDLE- } \\
\text { like }\end{array}$ & $\begin{array}{l}\text { recurrent inflammation, } \\
\text { digital ischemia, ulcers, } \\
\text { CS-dependency }\end{array}$ & $\begin{array}{c}\text { ETA, RTX, } \\
\text { CAN }\end{array}$ & TOF, CS & 0.25 & 43 & $\begin{array}{l}\text { MDA5 } \\
\text { NLRP3 }\end{array}$ & $\mathrm{CR}$ \\
\hline 9 & AID, IFP & $\begin{array}{l}\text { systemic inflammation, } \\
\text { ulcers }\end{array}$ & ETA & TOF, CS & 0.5 & 13 & & CR \\
\hline 10 & JIA, ERA & arthritis & ETA & TOF, MTX & 0.2 & 44 & & CR \\
\hline 11 & JIA, poly & arthritis & ABC, ETA & TOF, MTX & 0.25 & 38 & & $\mathrm{CR}$ \\
\hline 12 & JIA, poly & Arthritis, alopecia & ETA & TOF & 0.15 & 31 & & PR \\
\hline 13 & soJIA + MAS & $\begin{array}{c}\text { systemic inflammation, } \\
\text { arthritis }\end{array}$ & TCZ, CAN, ETA & TOF, CS & 0.5 & 38 & & NR \\
\hline 14 & JIA, poly & arthritis & $\begin{array}{c}\text { INX, ETA, ADA, } \\
\text { TCZ }\end{array}$ & TOF, MTX & 0.2 & 24 & & PR \\
\hline 15 & AID & $\begin{array}{l}\text { Systemic inflammation, } \\
\text { CS-dependency }\end{array}$ & TCZ & TOF,CS & 0.5 & 21 & STAT3, c1343A>C & PR \\
\hline 16 & JIA, ERA & arthritis & ETA & TOF & 0.25 & 21 & & PR \\
\hline 17 & JIA, poly & arthritis & ADA, TCZ, ETA & TOF & 0.15 & 39 & & $\mathrm{CR}$ \\
\hline
\end{tabular}

improvement of symptoms and disease activity or no response (NR) - no changes in disease activity.

Results: Mean duration of TOF treatment was $25.4 \pm 18.9$ months. TOF was used as monotherapy in 3 cases, in combination with methotrexate (MTX) in 6, and in combination with other biologics in 3 children: tocilizumab $(n=2)$ and canakinumab $(n=1)$. Nine patients received CS. (Table 1$)$. In two JIA patients with alopecia TOF induced intensive hair growth and controlled joint inflammation. 9 patients had CR: AID $(n=3)$, JIA $(n=4)$ and JDM $(n=1): 7$ patients had PR and 1 was NR. 13 patients had a previous history of several subsequent failed biologic: 4 biologics $(n=1), 3$ biologics $(n=6), 2$ biologics $(n=1), 1$ biologic $(n=5)$. TOF treatment allowed discontinuation of CS in patient\#6 and reducing the CS in 8/10 patients from 0.4 $\pm 0.27 \mathrm{mg} / \mathrm{kg}$ to $0.15 \pm 0.1 \mathrm{mg} / \mathrm{kg}$ in $3.7 \pm 3.4$ times: in 2 cases the tapering of steroids failed (Figure 1). 4 patients had side effects not requiring treatment discontinuation: liver enzymes elevation $(n=2)$, hypercholesterolemia $(n=1)$, lymphadenitis $(n=1)$. In pt\#6 after achievement of the remission the TOF dosage was decreased up to 2 times and tocilizumab intervals were increased up to 6 weeks.

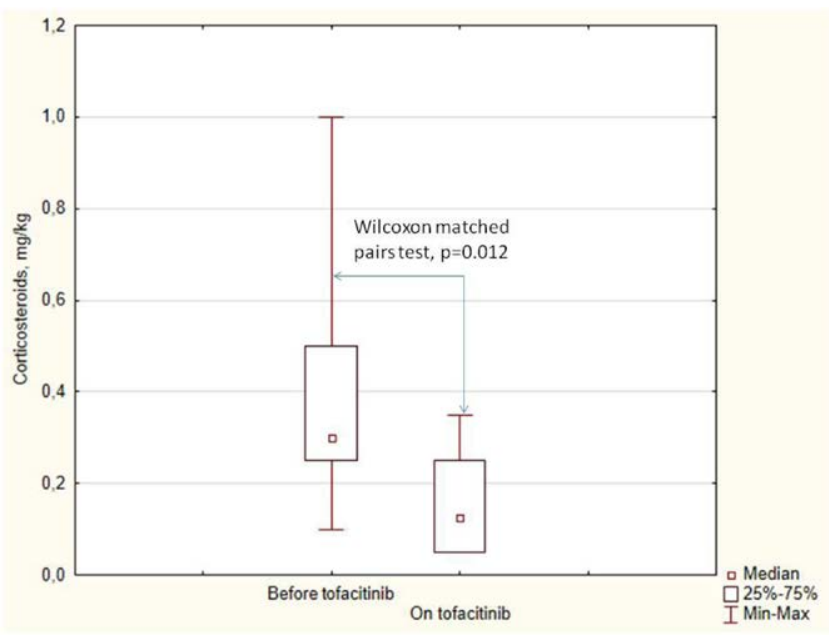

Figure 1.

Conclusion: Tofacitinib is a promising agent in treating pediatric rheumatic diseases. In our study the best results were in AID patients with rare alleles in interferon pathway genes, patients with arthritis and alopecia and in children with JDM. Future studies are needed to identify clear indications for treatment with JAK-inhibitors.

Acknowledgements: This work was supported by the RSF grant №20-45-01005. Disclosure of Interests: None declared.

DOI: 10.1136/annrheumdis-2021-eular.1913

\section{POS0081 CLINICAL FEATURES OF PEDIATRIC BEHÇET'S DISEASE IN CHINA}

S. Zheng', Z. Huang ${ }^{1}$, Y. Liu', Y. Huang ${ }^{1}$, T. W. Li Li. ' Guangdong Second Provincial General Hospital, Rheumatology, Guangzhou, China

Background: Behçet's disease (BD) is a systemic inflammatory disease involving primarily the oral and genital mucosa, skin and eyes. Some patients exhibit broader involvement with multi-organ system inflammation, causing significant morbidity and mortality. With much of the literature focused on adult-onset $\mathrm{BD}$, the clinical spectrum of $B D$ in children is not well studied. The diagnosis of pediatric $\mathrm{BD}$ is difficult to make due to its rarity in childhood, the paucity of experience among pediatricians and the lack of validated diagnostic criteria.

Objectives: We aim to describe the clinical characteristic of children with Behçet's disease in China.

Methods: We performed a cross-sectional cohort analysis of patients with BD recruited between June 2017 and May 2020. We enrolled a total of 848 patients with pediatric $\mathrm{BD}$ (onset prior to age 18 years) and 1531 patients with adult-onset BD. Clinical data were collected by retrospective chart review.

Results: From a cohort of 848 patients with pediatric BD (412 males, 436 females), the average age of disease onset was $11.59 \pm 4.11$ years and the earliest case was appeared the first symptom at 7 months of age. Clinical manifestations in this group included recurrent oral aphtosis $(100 \%)$, genital ulcers $(77.71 \%)$, ocular involvement $(30.19 \%)$, skin involvement $(63.56 \%)$, neurological involvement $(4.60 \%)$, gastrointestinal involvement $(20.05 \%)$, vascular involvement $(9.79 \%)$, heart valve involvement $(3.66 \%)$, arthritis / arthralgia $(32.43 \%)$, fever $(0.35 \%)$ and positive pathergy test $(21.11 \%$; Table 1$)$. The prevalence of these clinical findings was largely similar to that of adult BD patients with the exception of mild differences in the frequency of gastrointestinal, heart valve, joint involvement and fever. However, the time from symptom onset to diagnosis was significantly longer in children with $\mathrm{BD}$ compared to adults $(13.34 \pm 9.13$ years vs. $6.73 \pm 33.21$ years, $P<0.001)$. The most common initial symptom in pediatric $B D$ was recurrent oral aphtosis $(91.57 \%$ vs. $86.28 \%$ in adults, $P<0.001)$.

In the pediatric group, clinical manifestations also differed between males and females. In addition to oral ulcers, the most common clinical manifestations in male patients were ocular involvement (42.23\%), vascular involvement $(15.53 \%)$, heart 
valve involvement $(5.10 \%)$ and epididymitis (9.95\%). Among female patients, the frequency of genital ulcers is significantly higher than that of men $(86.24 \%$ vs. $68.69 \%$, $\mathrm{P}<0.001$ ).

Conclusion: We described the clinical characteristics of a large cohort of pediatric BD patients in China. While the clinical manifestations are largely similar to adult $\mathrm{BD}$, the time from symptom onset to diagnosis is significantly delayed in pediatric patients. Our study highlights the need to improve awareness of BD among pediatric providers to facilitate rapid diagnosis and treatment in children. REFERENCES:

[1] Yıldız et al. Pediatric Behçet's disease- clinical aspects and current concepts. Eur J Rheumatol 2020; 7(Suppl 1): S38-S47.

[2] Koné-Paut. Behçet's disease in children, an overview. Pediatric Rheumatology (2016) 14:10.

Table 1. Comparison of clinical features of BD in children and adults

\begin{tabular}{lccc}
\hline & $\begin{array}{c}\text { Children } \\
(\mathrm{n}=848)\end{array}$ & $\begin{array}{c}\text { Adult } \\
(\mathrm{n}=1531)\end{array}$ & $\mathrm{P}$ \\
\hline Age of first symptom $(\mathrm{y})$ & $11.59 \pm 4.11$ & $27.08 \pm 7.91$ & \\
Sex(M/F) & $412 / 436$ & $6.73 \pm 33.21$ & $<0.001$ \\
Years of diagnosis $(\mathrm{y})$ & $13.34 \pm 9.13$ & $1518(99.15 \%)$ & 0.007 \\
Recurrent oral aphthosis & $848(100 \%)$ & $1152(75.24 \%) 379$ & 0.176 \\
Genital Ulcers & $659(77.71 \%) 189$ & $508(33.18 \%) 1023$ & 0.134 \\
Ocular signs & $256(30.19 \%) 592$ & $1020(66.62 \%) 511$ & 0.132 \\
Cutaneous signs & $539(63.56 \%) 309$ & $82(5.36 \%) 1449$ & 0.421 \\
Neurological signs & $39(4.60 \%) 809$ & $244(15.94 \%) 1387$ & 0.001 \\
Gastrointestinal signs & $170(20.05 \%) 678$ & $162(10.58 \%) 1369$ & 0.542 \\
Vascular signs & $83(9.79 \%) 765$ & $110(7.18 \%) 1421$ & $<0.001$ \\
Heart valve signs & $31(3.66 \%) 817$ & $22(1.44 \%) 1509$ & $<0.001$ \\
Joint signs & $275(32.43 \%) 573$ & $347(22.66 \%) 1184$ & 0.013 \\
Fever & $3(0.35 \%) 845$ & & 0.381 \\
Positive pathergy test & $179(21.11 \%) 669$ & & \\
\hline
\end{tabular}

Acknowledgements: China Behcet' Disease Patients Assossiation.

Disclosure of Interests: None declared.

DOI: 10.1136/annrheumdis-2021-eular.3621

\begin{tabular}{|l|l}
\hline POS0082 & PERFORMANCES OF THE RISK FACTORS AND \\
PEDIATRIC VASCULITIS ACTIVITY SCORES \\
FOR DISEASE SEVERITY IN CHILDREN WITH \\
MULTISYSTEM INFLAMMATORY SYNDROME
\end{tabular}

B. Sözeri ${ }^{1}$, Ş. Çağlayan ${ }^{1}$, A. Akyol ${ }^{2}$, K. Ulu ${ }^{1}$, T. Coşkuner $^{1}$, C. Hasbal Akkuş ${ }^{2}$, F. Demir ${ }^{1} .{ }^{1}$ Health Sciences University, Umraniye Traning and Research Hospita, Pediatric rheumatology, Istanbul, Turkey; ${ }^{2}$ Health Sciences University, Umraniye Traning and Research Hospita, Pediatrics, Istanbul, Turkey

Background: Multisystem Inflammatory Syndrome in Children (MIS-C) is observed by hyperinflammation and cytokine storm. The spectrum of severity ranged from standard hospitalization to pediatric intensive care unit management. There is no specific activity score that predicts whether this hyperinflammatory state will be severe or result in mortality in pediatric patients. There are activity scores used in KD and other vasculitis such as Kobayashi score (KS) and Pediatric Vasculitis Activity Score (PVAS) that determine the severity of the disease in children.

Objectives: Based on the clinical similarity of MIS-C to these disease groups, we wanted to evaluate the performance of these disease activity scores. Also, we aimed to identify the factors associated with the disease severity of patients with MISC

Methods: We retrospectively enrolled a single-center cohort of 45 consecutive pediatric patients with MISC admitted to Umraniye Training and Resrach Hospital, Pediatric Rheumatology Clinic, Istanbul, Turkey, from April 20 to December 31, 2020. Medical information of each patient including demographic data, clinical characteristics, laboratory results, and outcomes was extracted retrospectively through review of electronic medical records. We analyzed all score systems including KS, PVAS, NLR, cHIS, and C-reactive protein/albumin ratio (CAR) as assessment factors for diagnosis for severe disease and evaluation of disease activity in MISC. All scores were compared between two groups and receiver operating characteristic (ROC) curve analysis was performed to evaluate diagnostic utility.

Results: We reported 45 patients (10 female, 35male) with MISC. Their mean age was $9.65 \pm 4.93$ years ( 7 months -18 years). All patients had fever (median 4 days), $71 \%$ patients had acute gastrointestinal symptoms, $37.8 \%$ of patient's conjunctivitis and only 5 patients had respiratory findings at admission. Twenty-four (46.7\%) patients met criteria for classic KD. Macrophage activation syndrome and myocardial dysfunction with or without cardiogenic shock were seen 14 and 10 patients respectively. All the patients had positive serology for SARSCoV-2, abnormal complete blood counts and coagulation tests, and elevated inflammatory markers.

We divided the disease severity into a moderate or severe group based on admission on intensive care unit (ICU). There were 15 patients with severe illness
(33\%). The median age of these patients was significantly older (11.3 years vs 9.16 years, $p=0.05)$. The median hospital stay period was 10 days. The median need for intensive care was on the first day (1-14th days), and the median lasted 5 (1-9) days. The majority of MISC patients were on Intravenous immunoglobulin (IVIG) $(89 \%)$, and corticosteroid $(73.3 \%)$. A total of 12 patients received anakinra In the severe group, all patients had higher values of KD, PVAS, NLR, cHIS, and CAR than the patients in moderate group. For severe MISC, the area under receiver operating characteristic curve (AUC) was $0.864(95 \%$ confidence interval $[\mathrm{Cl}], 0.729-1)$ for the PVAS, $0.911(95 \% \mathrm{Cl}, 0.827-0.995)$ for the NLR, and $0.853(95 \% \mathrm{Cl}, 0.744-0.963)$ for the CAR, with optimal cut-off values of 3.5 9.05 , and 4.86 , respectively. Thirty-eight $(84.4 \%)$ of the 45 patients met two or more cHIS criteria at the time of their hospitalization; $39 \%$ of these patients were identified as severe group (OR $1.62,95 \% \mathrm{Cl} 1.27-2.13, \mathrm{p}=0.04$ ). At the time of diagnosis, 29 patients with a Kobayashi score greater than 4 were detected, of which 15 required intensive care (OR 2.07, 95\% $\mathrm{Cl} 1.42-3.0, \mathrm{p}=0.00)$.

Conclusion: This study demonstrated that both inflammatory scores (CAR and NLR) and disease activity scores (KS, PVAS and cHIS) can be used to aid the assessment for severity of MISC

REFERENCES:

[1] Webb BJ, et al Lancet Rheumatol. 2020 Dec;2(12):e754-e763.

[2] Feldstein LR et al N Engl J Med. 2020;383(4):334-346

Disclosure of Interests: None declared.

DOI: 10.1136/annrheumdis-2021-eular.2916

\section{POS0083 \\ USEFUL EXPERIENCE OF RHEUMATOLOGISTS FOR UNDERSTANDING OF THE DISEASE ORIGIN AND APPROACHES TO THERAPY IN FIBRODYSPLASIA OSSIFICANS PROGRESSIVA}

I. Nikishina $^{1}$, S. Arsenyeva ${ }^{1}$, V. Matkava ${ }^{1}$, A. Arefieva $^{1}$, M. Kaleda ${ }^{1}$,

T. Pachkoria', Z. Kolkhidova ${ }^{1}{ }^{1}$ V.A. Nasonova Research Institute of Rheumatology, Paediatric, Moscow, Russian Federation

Background: Many monogenic genetic conditions, such as auto-inflammatory diseases (AIDs), have similar clinical manifestations and immunopathogenesis to "classic" rheumatic diseases (RD). Such cases may include Fibrodysplasia ossificans progressiva (FOP), an extremely rare genetic disease, which, according to our previous study and data from other authors 1 , may represent an example of AID with catastrophic heterotopic ossification due to a mutation in the ACVR1 gene. it seems that the experience of rheumatologists, especially children's ones, will be useful in the treatment of FOP.

Objectives: To analyzed the dynamics of clinical manifestations and to therapy approaches including target anti-inflammatory drug Tofacitinib (TOFA) in the one of the world's largest groups of patients (pts) with FOP.

Methods: The study was based on the analysis retrospective and prospective observation of the 35 pts ( 17 males and 18 females) with a verified diagnosis of FOP for the period from 1998 to 2020 . In 9 pts with severe course of FOP TOFA administration were evaluated.

Results: In all 35 pts the diagnosis was verified by "classic" FOP phenotype: malformed great toes in 33 pts $(94,3 \%)$; short malformed thumbs- 8 (22.8\%); peripheral osteochondromas-20 (57.1\%); abnormalities of the cervical spine-32 (91.4\%), multiple heterotopic ossifications-32 (91,4\%). Genetic tests were done in 26 , it confirmed mutation in the ACVR1 gene in $100 \%$. Long term follow-up detected a lot of spondyloarthritis-like signs similar to the manifestation of RD: ankylosis of the facet joints and vertebral bodies (by the type of syndesmophytes) in most pts, sacroiliitis, confirmed by radiological methods (X-ray, CT, MRI), gradual ankylosis in the peripheral joints in 18 (56.4\%), synovitis in large joints in 8 (25\%) pts (knee and hip mostly). In 9 pts with the most difficult course with rapid progression of ossification due to continuous flares despite the NSAIDs and steroids intake, we tried to use TOFA after the approval of the local Ethic Committee. We use the similar dose to randomized trial for JIA (up to $5 \mathrm{mg}$ twice a day). The first patient was 16 y.o. at the time of TOFA administration in December 2019, the age of the other pts was from 2 to 12 y.o. By present time duration of TOFA therapy is from 6 to $15 \mathrm{mo}$. For the previous 6 months before TOFA initiation the number of flares was in average 8 per patient. After 6 months of TOFA treatment the number of new flares decreased to $0-1$, except youngest patient of 2 y.o. in whom the number of flares decreased from 10 to 4 per the same period. In all 9 pts we minimize the dose or completely stop the steroids. New nodes formation stopped immediately in most pts and also the significant motion improvement of large (shoulder) joints were established. Drug tolerance was good in all pts, no AE were registered. But despite the good clinical effect without new heterotopic ossification in our first patient, we found continuous intraskeletal ossification between vertebral bodies, facet and sacroiliac joints in MRI Conclusion: We are confident that the processes of heterotopic ossification in FOP are very similar to new born formation phenomenon in spondyloarthritis and reliable suppression of inflammation can interrupt the progression of the disease. We used similar justifications to our colleagues for the use of anti-cytokine drugs, but used a JAK-kinase inhibitor, it was extremely important the oral rout of drug administration and possibility to escape any injections in FOP. TOFA demonstrated positive effect 